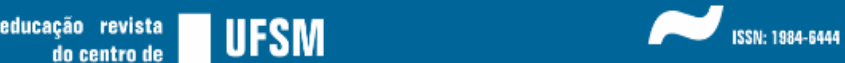

\section{Formação do psicólogo na Bahia: uma análise a partir do Enade 2015}

\author{
Psychology Education and Training in Bahia, Brazil: an analysis of
}

\section{Enade 2015}

\section{Caio Rudá}

Universidade Federal do Sul da Bahia, Itabuna, Bahia, brasil.

caioruda.o@gmail.com - https://orcid.org/0000-0002-4252-9979

\section{Gabriela Andrade da Silva}

Universidade Federal do Sul da Bahia, Itabuna, Bahia, brasil.

gabriela.silva.ufsb@gmail.com - https://orcid.org/0000-0002-4188-0935

Recebido em 13 de setembro de 2018

Aprovado em 18 de outubro de 2018

Publicado em 31 de janeiro de 2020

\section{RESUMO}

No âmbito do Sistema Nacional de Avaliação da Educação Superior (SINAES), o Exame Nacional de Desempenho de Estudantes (Enade) é uma das principais ferramentas de avaliação do ensino superior. O objetivo deste artigo é justamente analisar o desempenho dos estudantes de Psicologia no exame realizado em 2015, apresentando um recorte geográfico circunscrito ao estado da Bahia. Foi realizado um estudo quantitativo, com base nos dados do Enade 2015 disponibilizados no Portal do Instituto Nacional de Estudos e Pesquisas Educacionais Anísio Teixeira (INEP). Os cursos foram identificados pelo nome da instituição e município. Foram consideradas na análise as variáveis: organização acadêmica, categoria administrativa, indicadores do desempenho dos estudantes. Os resultados apontam para um processo de interiorização da formação do psicólogo, capitaneada pela rede particular de ensino. De modo geral, verificou-se também que não houve um desempenho significativamente distinto dos cursos no interior em relação aos cursos da capital, todos eles com desempenho mediano ou fraco, compatível com a média nacional. Universidades públicas apresentaram desempenho significativamente superior em relação a faculdades e centros universitários privados. Embora não tenha sido possível estabelecer se as diferenças significativas no desempenho se deveram à organização acadêmica ou à categoria administrativa, a predominância do setor privado, majoritariamente estruturado em faculdades e centros, indica um cenário de precarização do ensino no estado. É, portanto, preocupante o cenário de formação em Psicologia na Bahia, com um perverso processo de interiorização marcado pela 


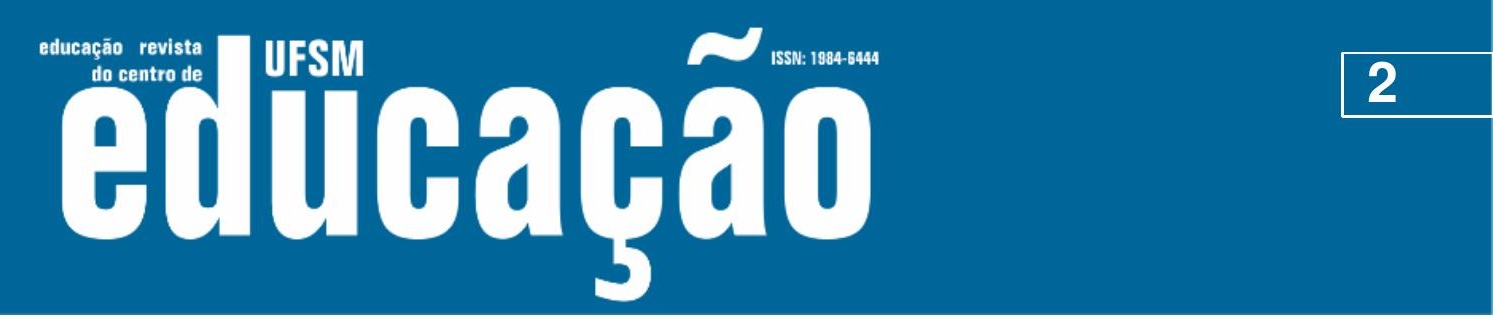

ISSN: 1984-6444 | http://dx.doi.org/10.5902/1984644434755

presença do mercado, sem a devida garantia da qualidade do ensino, e cujo impacto na atuação profissional merece ser avaliado.

Palavras-chave: Formação em Psicologia; Enade; Educação Superior.

\section{ABSTRACT}

The National Examination of Student Performance (Exame Nacional de Desempenho de Estudantes/Enade) is one of the main tools for the evaluation of higher education in Brazil. This article aims to analyze the performance of Psychology students in the Enade 2015 in the state of Bahia, Brazil. A quantitative study was carried out, based on the Enade 2015 data made available by the Brazilian government. The following variables were included in the analysis: academic organization, administrative category and indicators of students' performance. The results pointed to a trend of higher education courses to multiply within the state of Bahia, headed by the private sector. In general, students enrolled to courses outside the capital of the state did not perform differently from the student in capital, all of them with medium or weak performance, compatible with the national average. Public universities have performed significantly better than private colleges. Although it was not possible to establish whether the significant differences in performance were due to the academic organization or to the administrative category, the predominance of the private sector, mostly represented by faculdades and centros universitários, indicates a scenario of precariousness of education in the state. It is, therefore, of concern the educational scenario in Psychology in Bahia, shaped by a perverse process of expansion inside the state marked by the presence of the for-profit higher education institutions, without ensuring the quality of teaching, and whose impact on the professional performance deserves to be evaluated.

Keywords: Education and Training in Psychology; Assessment and Evaluation; Higher Education.

\section{Introdução}

Instituído com a Lei oㅜ 10.861, de 14 de abril de 2004, o Sistema Nacional de Avaliação da Educação Superior (SINAES) é o resultado da ampliação da experiência nacional desenvolvida na década anterior, a partir do Programa de Avaliação Institucional (PAIUB) e o Exame Nacional de Cursos (ENC), articulando a natureza formativa da avaliação com os processos de regulação (supervisão e fiscalização) exercidos pelo Estado, num sistema amplo e complexo (VERHINE, 2015). 


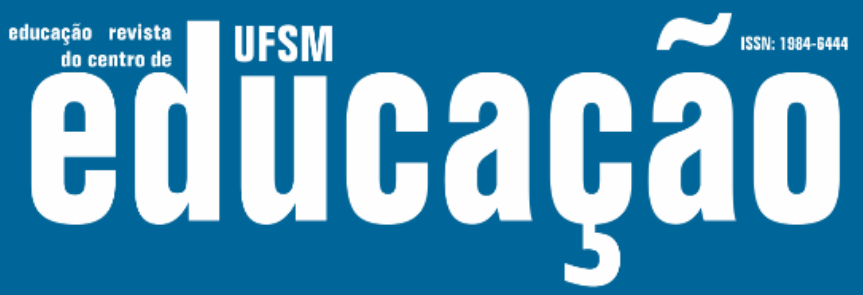

ISSN: 1984-6444 | http://dx.doi.org/10.5902/1984644434755

Desde então, todos os processos avaliativos vinculados ao SINAES têm sido coordenados pela Comissão Nacional de Avaliação da Educação Superior (CONAES) e operacionalizados pelo Instituto Nacional de Estudos e Pesquisas Educacionais Anísio Teixeira (INEP), órgão oficial de avaliação de todos os níveis educacionais no país, vinculado ao Ministério da Educação (MEC).

Observa-se, desse modo, que o Brasil não foge à regra no que respeita à questão da avaliação educacional, que tem ganhado cada vez mais importância no cenário de globalização e da internacionalização do ensino superior. Concebida como um processo dinâmico, oferece subsídios para que as instituições de ensino superior (IES) "disponham de evidências empíricas não apenas de suas debilidades, mas também de suas potencialidades e de suas realizações" (BRITO, 2008, p. 841), sendo possível orientá-las em direção às metas estabelecidas, institucional e socialmente.

No caso nacional, ao articular-se também ao âmbito de regulação, a avaliação configura-se como instrumento legítimo de garantia de qualidade, eficiência e prestação de contas, a partir do cumprimento de padrões mínimos (VERHINE; FREITAS, 2012). No entanto, encontram-se algumas considerações negativas acerca da implementação do SINAES. Tais críticas incidem sobre a desvirtuação da proposta original que visava à garantia de uma avaliação formativa, em decorrência dos diversos ajustes que foram operados para garantir a exequibilidade de uma proposta avaliativa abrangente no âmbito de um sistema educacional em expansão, e, em parte, do acirramento da perspectiva técnico-burocrática ensejado pela vinculação do processo avaliativo ao expediente regulatório (SOUSA; SEIFFERT; FERNANDES, 2016; POLIDORI, 2009; LIMANA, 2008; DIAS SOBRINHO, 2008).

A despeito das críticas, o SINAES desponta como uma política importante de avaliação, necessária a um sistema de ensino que, em 2015, totalizava 2.364 IES, 33.501 cursos de graduação e 8.027.297 matrículas, das quais $75,7 \%$ se encontravam na rede privada de ensino (BRASIL, 2018).

No âmbito do SINAES, o Exame Nacional de Desempenho de Estudantes (Enade) tornou-se uma das principais ferramentas de avaliação do ensino superior, constituindo a dimensão da avaliação do desempenho estudantil, um dos três eixos analisados, juntamente com a avaliação institucional e a avaliação de cursos. 


\section{Autuaŗão}

ISSN: 1984-6444 | http://dx.doi.org/10.5902/1984644434755

Composto de duas partes - formação básica e componentes específicos -, seu objetivo, preconizado na Lei no $10.861 / 04$, é aferir

o desempenho dos estudantes em relação aos conteúdos programáticos previstos nas diretrizes curriculares do respectivo curso de graduação, suas habilidades para ajustamento às exigências decorrentes da evolução do conhecimento e suas competências para compreender temas exteriores ao âmbito específico de sua profissão, ligados à realidade brasileira e mundial e a outras áreas do conhecimento (BRASIL, 2004, n/p).

O Enade 2015 objetivou avaliar o desempenho dos estudantes concluintes dos cursos mencionados na Portaria Normativa ํo 03/2015 (BRASIL, 2015), entre eles, os cursos de Psicologia. Para tanto, os estudantes inscritos responderam, antes da realização da prova, a um questionário on-line, cuja função era compor o perfil discente e investigar a infraestrutura e a organização acadêmica do seu curso. Os coordenadores dos cursos também responderam a um questionário com questões semelhantes às formuladas para os estudantes e que permitiram uma comparação (BRASIL, 2016a).

O exame, propriamente, foi composto por uma prova contendo questões de múltipla escolha e discursivas, pautadas em dois componentes estruturantes: o primeiro, denominado Componente de Formação Geral (FG), consiste na parte comum às provas das diferentes áreas, avaliando competências, habilidades $\mathrm{e}$ conhecimentos gerais; o segundo, denominado Componente de Conhecimento Específico (CE), contempla a especificidade de cada área no domínio dos conhecimentos e habilidades esperados para o perfil profissional (BRASIL, 2016a).

Assim, o FG avalia competências e habilidades que, embora não sejam específicas da área de Psicologia, são relevantes à formação e ao exercício profissional, como por exemplo, leitura, interpretação e produção de textos; raciocínio indutivo e dedutivo; capacidade de análise e síntese; capacidade de projetar intervenções e propor soluções para situações-problema; e administração de conflitos. Os conteúdos foram variados, envolvendo cultura e arte, tecnologias, democracia, ética e cidadania, ecologia, política, relações de trabalho, responsabilidade social, sociodiversidade e multiculturalismo, vida urbana e rural. O FG foi composto por dez questões, sendo duas discursivas e oito de múltipla escolha, abordando situações- 


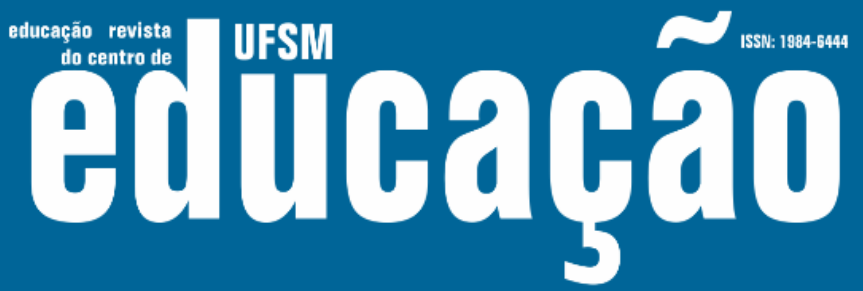

ISSN: 1984-6444 | http://dx.doi.org/10.5902/1984644434755

problema e estudos de caso, simulações, interpretação de textos e informações numéricas (BRASIL, 2016a).

O CE, por sua vez, foi baseado no perfil profissional das Diretrizes Curriculares Nacionais para os Cursos de Graduação em Psicologia (BRASIL, 2011). Foram avaliadas competências e habilidades como, por exemplo: formular condutas profissionais com base em evidências científicas; usar métodos de investigação científica; identificar e analisar necessidades de natureza psicológica; elaborar projetos; planejar e agir de forma coerente com referenciais teóricos e características da população-alvo; elaborar textos acadêmicos e técnicos; utilizar os recursos matemáticos e computacionais; atuar em processos educativos, de gestão, de prevenção e promoção da saúde, de assistência e apoio psicossocial; realizar psicodiagnóstico, psicoterapia e outras estratégias clínicas; coordenar e manejar processos grupais; e avaliar os resultados e impactos das intervenções psicológicas conduzidas. Quanto aos conteúdos, foram abordados cinco eixos, a saber: I Fundamentos epistemológicos e históricos; II - Fundamentos, métodos e técnicas de coleta e análise de dados para investigações científicas; III - Fenômenos psicológicos; IV - Principais domínios de atuação do Psicólogo; V - Princípios éticos e deontológicos no exercício profissional. O CE foi composto por 30 (trinta) questões, sendo 3 (três) discursivas e 27 (vinte e sete) de múltipla escolha, envolvendo situações-problema e estudos de casos (BRASIL, 2016a).

As Notas Brutas dos componentes (que podem variar de zero a cem) são usadas para calcular uma série de indicadores referentes aos cursos avaliados. Inicialmente, calcula-se o desempenho médio de cada curso nos componentes FG e CE. A seguir, calculam-se as médias e os desvios padrões nacionais para o FG e o $\mathrm{CE}$, a partir das notas médias de todos os cursos nos respectivos componentes. Com base nesses resultados, calcula-se $o$ afastamento padronizado de cada curso para os componentes $\mathrm{FG}$ e $\mathrm{CE}$, que é um indicador do afastamento do curso em relação à média nacional (BRASIL, 2016a).

A partir dos afastamentos padronizados, são calculadas as Notas Padronizadas dos componentes FG e FE para cada curso, as quais variam numa escala de zero a cinco. Nesse cálculo, cursos com afastamento padronizado menor que $-3,0$ ou maior 




ISSN: 1984-6444 | http://dx.doi.org/10.5902/1984644434755

que 3,0 (isto é, aqueles que apresentam notas médias com grande discrepância em relação à média nacional - os chamados outliers) recebem Nota Padronizada igual a zero ou cinco, respectivamente, e não são usados como valor mínimo ou máximo na fórmula de cálculo da Nota Padronizada dos demais cursos (BRASIL, 2016a).

Por fim, calcula-se a Nota dos Concluintes do Enade 1, que é a média ponderada das notas padronizadas do curso nos componentes FG e CE. Para isso, são considerados os pesos de $25 \%$ para $F G$ e $75 \%$ para CE, respeitando, portanto, a proporcionalidade do número de questões de cada prova. As Notas dos Concluintes do Enade (valor contínuo) são transformadas em cinco faixas (valores discretos), que correspondem ao Conceito Enade (BRASIL, 2016a).

Embora o Enade tenha sido aplicado trienalmente desde 2006, contando, até o momento, com três edições, uma busca na base de dados Biblioteca Virtual em Saúde - Psicologia (BVS-Psi) retornou apenas duas análises de resultados referentes à sua primeira edição, em 2006, (SOUZA; BASTOS; BARBOSA, 2011; BASTOS et al., 2011), o que indicou uma lacuna no conhecimento científico que pode ser construído a partir das avaliações subsequentes.

Assim, considerando os limites de um exame dessa natureza, o qual pode deixar de lado a avaliação de importantes elementos do processo de formação, como as competências adquiridas em atividades de pesquisa e extensão (FELDMANN; SOUSA, 2016), o presente artigo objetiva analisar a formação do psicólogo em instituições de ensino superior (IES), a partir do desempenho dos estudantes no Enade 2015, apresentando um recorte geográfico circunscrito ao estado da Bahia. Aproxima-se, portanto, da temática da formação do psicólogo, amplamente discutida desde antes da sua institucionalização com a Lei no 4.116/62.

\section{A Psicologia na Bahia: um panorama}

Fora do eixo sul-sudeste, no qual majoritariamente se desenvolveu a Psicologia brasileira, a Bahia é atualmente uma das unidades federativas que merecem destaque no que respeita à formação do psicólogo. Implementado em 1968, o curso de Psicologia da Universidade Federal da Bahia foi, até 2001, o único espaço de 


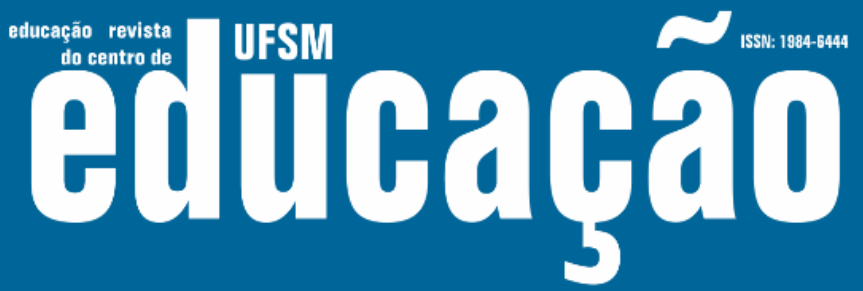

ISSN: 1984-6444 | http://dx.doi.org/10.5902/1984644434755

formação, quando foi então autorizado o segundo curso no estado, em instituição privada.

No âmbito público, só em 2006 surgiu outro curso de graduação na área, na Universidade Federal do Recôncavo da Bahia. Vale destacar que esse curso foi implantado no contexto político de investimento na expansão das Instituições de Ensino Superior Federais, pela ampliação do número de vagas nas IES já existentes, criação de novos campi (buscando a interiorização das IES) e de novas universidades (MARQUES; CEPÊDA, 2012). Em 2007, foi implantado o Programa de Apoio a Planos de Reestruturação e Expansão das Universidades Federais (Reuni), que teve como objetivo ampliar o acesso e a permanência na educação superior, por meio de um melhor aproveitamento de recursos físicos e humanos das universidades federais (BRASIL, 2007).

As instituições privadas tiveram expansão ainda mais expressiva, alcançando, entre 1995 e 2010, crescimento de $207 \%$ no Brasil e 583\% na macrorregião Nordeste (MARQUES; CEPÊDA, 2012). Consequentemente, na Bahia, atualmente se vive um cenário distinto, marcado pela proliferação de cursos, cada vez mais interiorizados, alcançando regiões remotas do estado. Em 2015, havia 39 instituições, que ofereciam 41 cursos, em 17 municípios, totalizando 13.782 matrículas (BRASIL, 2016b).

Em 2017, foram ofertados 49 cursos de graduação, em 46 instituições distintas, localizadas em 21 cidades (MINISTÉRIO DA EDUCAÇÃO, 2017). Observa-se, conforme Figura 1, uma distribuição de cursos ao longo de todas as mesorregiões do estado, com o maior número deles sediados na Mesorregião Metropolitana de Salvador, onde se localizam a capital e maior polo industrial do estado: são 23 cursos nessa mesorregião (47\%), contra 6 cursos na Mesorregião do Centro-Norte Baiano (12\%), 6 cursos na Mesorregião do Centro-Sul Baiano (12\%), 5 cursos na Mesorregião do Nordeste Baiano (10\%), 4 cursos na Mesorregião do Sul Baiano (8\%), 4 cursos na Mesorregião do Extremo-Oeste (8\%) e apenas 1 curso na Mesorregião do Vale São-Franciscano (2\%).

Entre 2007 e 2017, houve um aumento de 118\% no número de cursos, configurando o maior aumento entre os estados da Federação, seguido pelo Ceará com um aumento de $116 \%$. São Paulo, por sua vez, o estado com o maior número de 


\section{Autuaŗão}

ISSN: 1984-6444 | http://dx.doi.org/10.5902/1984644434755

cursos, teve um crescimento de $25 \%$ nesse mesmo intervalo (MINISTÉRIO DA EDUCAÇÃO, 2017; LISBOA; BARBOSA, 2009). Tal ampliação se deu pela abertura de novos cursos na mesorregião metropolitana, sobretudo na capital, Salvador, bem como a partir de um movimento de interiorização da educação superior, tanto pelo setor privado quanto pelo setor público, embora este em menor escala se comparado ao setor privado.

Figura 1 - Distribuição geográfica dos cursos de Psicologia na Bahia

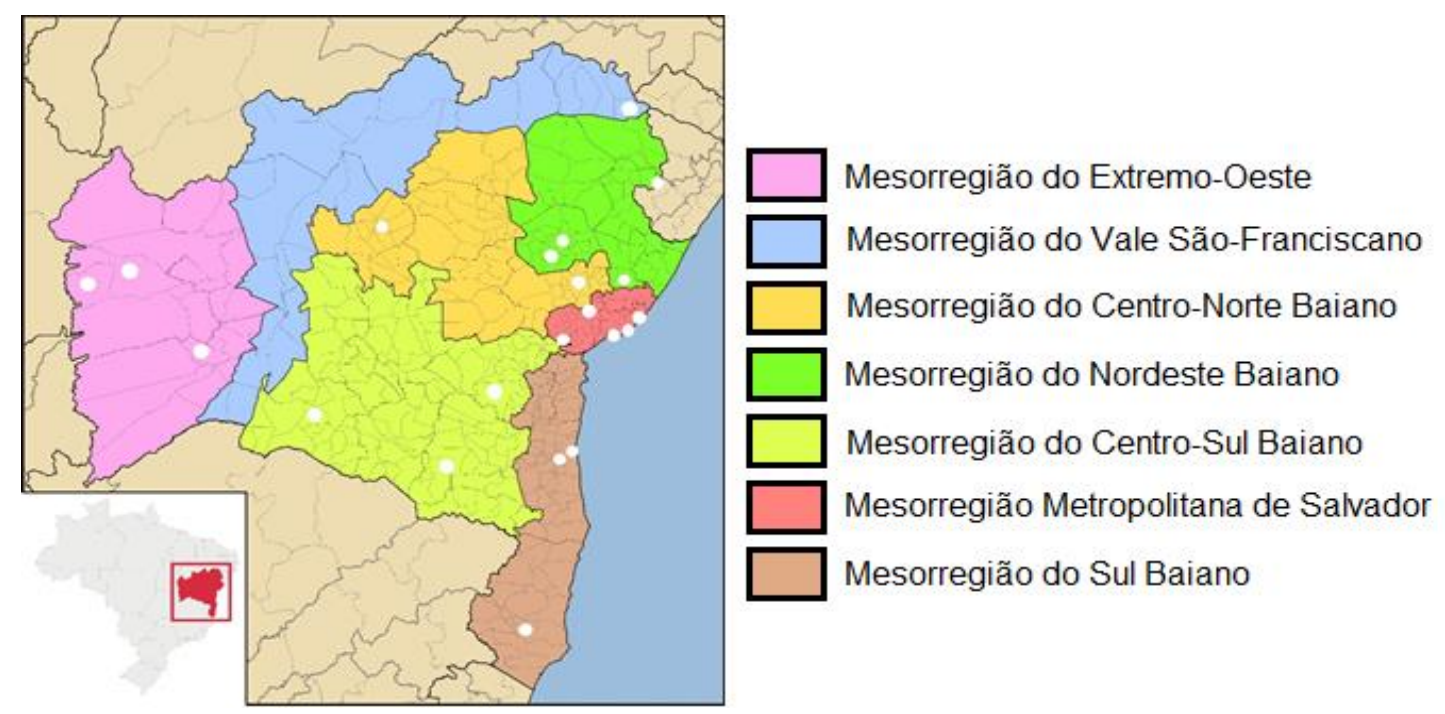

Fonte: elaboração própria

Com relação ao número de psicólogos inscritos, o Conselho Regional de Psicologia/03, correspondente ao estado da Bahia, registrou em novembro de 2017 11.877 inscrições, do total de 303.564 psicólogos em todo o território nacional (CONSELHO FEDERAL DE PSICOLOGIA, 2017), significando 3,91\% dos psicólogos inscritos, sendo o sétimo estado com maior número de inscrições e o primeiro fora do eixo Sul-Sudeste. A macrorregião Nordeste apresentou a segunda menor taxa de psicólogos em relação ao tamanho da população (8,3 por 10 mil habitantes), superior apenas à da região Norte (7,5 por 10 mil habitantes) e amplamente inferior à da região Sudeste, que apresenta a maior taxa (19,4 por 10 mil habitantes). Nesse contexto, embora tenha o maior PIB da macrorregião Nordeste (correspondendo a 3,9\% do PIB nacional), o estado da Bahia, com população de 15.370.128 habitantes, em 2017 


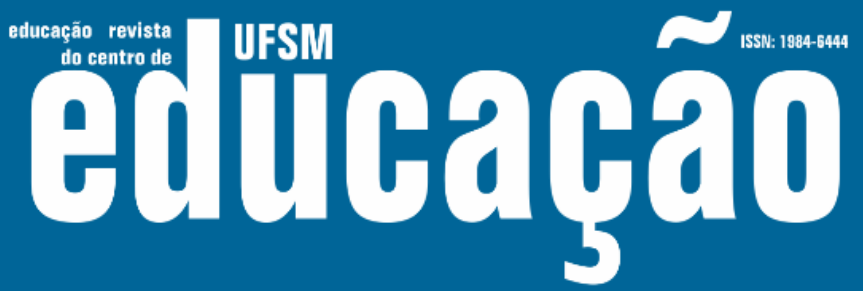

ISSN: 1984-6444 | http://dx.doi.org/10.5902/1984644434755

apresentou 7,7 psicólogos a cada 10 mil habitantes, taxa correspondente a cerca de metade da média nacional, de 14,6 psicólogos a cada 10 mil habitantes. A taxa de psicólogos em relação ao tamanho da população também é inferior à de outros estados da macrorregião Nordeste com menor participação no PIB nacional, como Pernambuco (11,2 por 10 mil habitantes), Alagoas (10,9 por 10 mil habitantes) e Paraíba (10,6 por 10 mil habitantes), por exemplo².

Se por um lado os dados apontam para uma realidade de expansão da educação superior, por outro é preciso atentar para este crescimento, dadas as constantes queixas da falta de qualidade do ensino privado, desde a década de 1960 (TEIXEIRA, 1968; BASTOS; GOMIDE, 1989; SILVA JÚNIOR; SGUISSARDI, 2005; CHAVES, 2014), o qual era, em 2015, responsável por $92 \%$ das matrículas nos cursos de Psicologia no estado (BRASIL, 2018). Decorre daí, portanto, a importância de investigar o desempenho das IES, num cenário de crescimento acentuado da formação do psicólogo no território baiano.

\section{Método}

Foi realizado um estudo quantitativo, com base nos dados do Enade 2015 disponibilizados no Portal do INEP. Os cursos foram identificados pelo nome da instituição e município. Foram consideradas na análise as variáveis:

1. Organização acadêmica (universidade, faculdade ou centro universitário), que tem se mostrado fator associado com a qualidade dos cursos em estudos anteriores (SOUZA; BASTOS; BARBOSA, 2011; BRASIL, 2016b). Por terem sido constatadas poucas instituições cuja organização acadêmica correspondeu a centro universitário, estas foram agrupadas às faculdades para as análises do presente artigo.

2. Categoria administrativa, também associada com qualidade dos cursos em pesquisas anteriores (SOUZA; BASTOS; BARBOSA, 2011; INEP, 2016b). Embora os dados disponibilizados pelo INEP classificassem as instituições em 10 categorias (Pessoa Jurídica de Direito Privado com fins lucrativos Sociedade Civil, Pessoa Jurídica de Direito Privado com fins lucrativos - 


\section{Autuaŗão}

ISSN: 1984-6444 | http://dx.doi.org/10.5902/1984644434755

Sociedade Mercantil ou Comercial, Pessoa Jurídica de Direito Privado sem fins lucrativos - Associação de Utilidade Pública, Pessoa Jurídica de Direito Privado - sem fins lucrativos - Fundação, Pessoa Jurídica de Direito Privado sem fins lucrativos - Sociedade, Pessoa Jurídica de Direito Público - Estadual, Pessoa Jurídica de Direito Público - Federal, Pessoa Jurídica de Direito Público Municipal, Privada com fins lucrativos, Privada sem fins lucrativos), por o estado da Bahia ter um número reduzido de cursos e, portanto, de unidades de observação, optou-se por agrupá-los em duas categorias: instituição pública (incluindo as classificadas como pessoa jurídica de direito público municipal, estadual e federal) e instituição privada (as demais).

3. Indicadores do desempenho dos estudantes: nota geral da prova (bruta e ponderada), nota do componente de formação geral (bruta e ponderada), nota do componente de formação específica (bruta e ponderada), conceito Enade contínuo e conceito Enade em faixas.

As seguintes hipóteses foram elaboradas com base em resultados de estudos anteriores (LISBOA; GONÇALVES, 2009; SOUZA; BASTOS; BARBOSA, 2011; INEP, 2016b): Hipótese 1: A Bahia teria desempenho semelhante aos demais cursos nacionais, em todos os indicadores. Hipótese 2: Instituições localizadas na capital teriam desempenho semelhante às localizadas no interior. Hipótese 3: Universidades teriam desempenho superior às faculdades ou centros universitários, em todos os indicadores. Hipótese 4: Instituições públicas teriam desempenho superior às instituições privadas, em todos os indicadores.

O programa IBM SPSS 20.0 foi usado para as análises. Inicialmente, foram examinadas as frequências para as variáveis discretas e as médias, desvios padrões, valor mínimo e máximo para as variáveis contínuas. Para os testes de hipóteses, foram realizados testes t para amostras independentes, adotando-se um nível de confiança de 95\%. Trata-se de um teste para avaliar a significância estatística da diferença entre as médias de duas amostras, para uma só variável dependente (HAIR et al., 2009). Para checar a homogeneidade das variâncias da variável dependente em relação aos dois grupos em análise, foi usado o teste de Levene, adotando-se os 


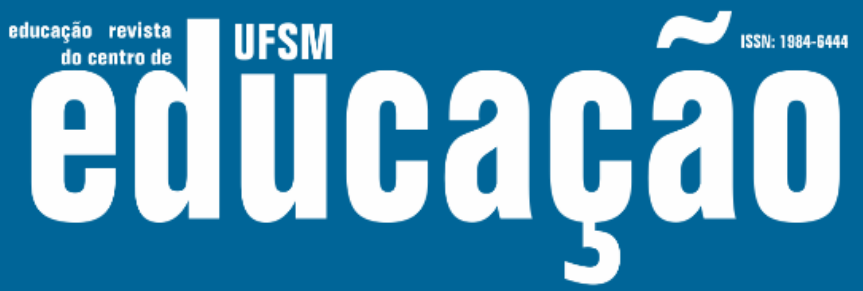

ISSN: 1984-6444 | http://dx.doi.org/10.5902/1984644434755

valores do teste $t$ adequados para os casos em que a homogeneidade foi aceita ou rejeitada.

\section{Resultados e discussão}

Em 2015, estudantes de 33 cursos de Psicologia do estado da Bahia participaram do Enade. Os cursos pertencem a 32 instituições de ensino superior, pois a Universidade Federal da Bahia oferta cursos de Psicologia em dois municípios (Salvador e Vitória da Conquista). Um curso (Faculdade Pitágoras de Teixeira de Freitas) não obteve conceito Enade, pois menos de dois concluintes participaram da prova. Portanto, a amostra final foi composta por 32 cursos, de 31 instituições de ensino superior.

Os cursos encontravam-se em 14 municípios, sendo quase a metade deles na capital, Salvador (14 cursos, correspondendo a $42,4 \%$ do total), resultado semelhante ao encontrado por um estudo realizado com os dados nacionais do Enade de Psicologia, que apontou que 38\% localizavam-se nas capitais (LISBOA; BARBOSA, 2009). Feira de Santana e Vitória da Conquista tiveram o segundo maior número de cursos de Psicologia do estado da Bahia (três cursos), seguidas por Itabuna e Alagoinhas (dois cursos em cada município). Não foram encontradas diferenças estatisticamente significativas entre as médias dos indicadores do Enade 2015 nos cursos da capital (Salvador) e do interior do estado da Bahia. O desempenho foi semelhante nas notas brutas do $F G\left(t_{30}=0,108, p=0,914\right)$, CE $\left(t_{30}=0,733, p=0,470\right)$, geral $\left(t_{30}=0,599, p=0,554\right)$ e na Nota dos Concluintes do Enade $\left(t_{30}=0,575, p=0,570\right)$. Portanto, a avaliação dos cursos por meio do Enade indicou que o processo de interiorização do ensino superior em Psicologia na Bahia não esteve associado com uma diferença na qualidade do processo de ensino-aprendizagem. Esse resultado corroborou o de Souza, Bastos e Barbosa (2011), que encontraram notas semelhantes entre cursos de Psicologia das capitais e do interior do Brasil no Enade 2006.

As estatísticas descritivas relativas ao desempenho dos cursos de Psicologia no Enade 2015 foram apresentadas na Tabela 1. As notas gerais brutas do Enade 


\section{HEM edturapao

ISSN: 1984-6444 | http://dx.doi.org/10.5902/1984644434755

dos 32 cursos avaliados variaram entre 36,98 e 63,49, com média de 47,13 e desvio padrão de 6,69. Portanto, o desempenho dos estudantes no exame foi mediano ou fraco. Essa constatação deve ser interpretada com cautela, pois é necessário ponderar a provável desmotivação dos estudantes ao participar de uma prova sem consequências diretas para sua formação ou carreira, conforme já relatado na literatura, bem como as críticas ao modelo de avaliação adotado (SANTOS; AFONSO, 2016; LEITÃO et al., 2010). Ademais, a média do estado da Bahia não diferiu significativamente ( $\left.t_{459}=0,198, p=0,843\right)$ dos 429 cursos de outros estados brasileiros (média $=46,92$, desvio padrão $=5,74$ ), indicando que problemas relativos à qualidade da formação dos psicólogos são de ordem nacional.

A média das notas brutas dos cursos foi superior no componente $F G$ (média = 56,55 , desvio padrão $=6,51$ ) em relação ao $\mathrm{CE}$ ( édia $=43,98$, desvio padrão $=6,99$ ), resultado semelhante ao encontrado na edição de 2006 do Enade (SOUZA; BASTOS; BARBOSA, 2011), e que revelou que os cursos têm apresentado desempenho inferior justamente nas competências e habilidades específicas da profissão, as quais foram estabelecidas pelas Diretrizes Curriculares Nacionais. O desempenho superior no FG não representa, necessariamente, um incremento em relação às habilidades e competências já adquiridas na formação pregressa, visto que estudo anterior, que comparou os desempenhos de estudantes no início e no final do curso, apontou diferenças mínimas nas notas do FG nesses dois momentos (SOUZA; BASTOS; BARBOSA, 2011).

Tabela 1 - Estatísticas descritivas relativas aos indicadores do Enade 2015 dos cursos de Psicologia: valores mínimo e máximo, médias e desvios padrões.

\begin{tabular}{l|c|c|c|c}
\hline \multicolumn{1}{c|}{ INDICADOR } & MÍNIMO & MÁXIMO & MÉDIA & $\begin{array}{c}\text { DESVIO } \\
\text { PADRÃO }\end{array}$ \\
\hline $\begin{array}{l}\text { Componente de Formação Geral (FG) - nota bruta } \\
\begin{array}{l}\text { Componente de Formação Geral (FG) - nota } \\
\text { padronizada }\end{array}\end{array}$ & 45,3 & 77,7 & 56,5 & 6,513 \\
\hline $\begin{array}{l}\text { Componente de Conhecimentos Específicos (CE) - } \\
\text { nota bruta }\end{array}$ & 33,7 & 5,000 & 2,4841 & 0,882 \\
\hline $\begin{array}{l}\text { Componente de Conhecimentos Específicos (CE) - } \\
\text { nota padronizada }\end{array}$ & 1,126 & 4,656 & 2,5722 & 0,986 \\
\hline Nota Geral bruta & 37,0 & 63,5 & 47,1 & 6,693 \\
\hline Nota Geral padronizada & 0,281 & 5,000 & 2,0886 & 1,192 \\
\hline Nota dos Concluintes do Enade & 1,116 & 4,742 & 2,5502 & 0,938 \\
\hline
\end{tabular}

Fonte: Elaboração própria. 


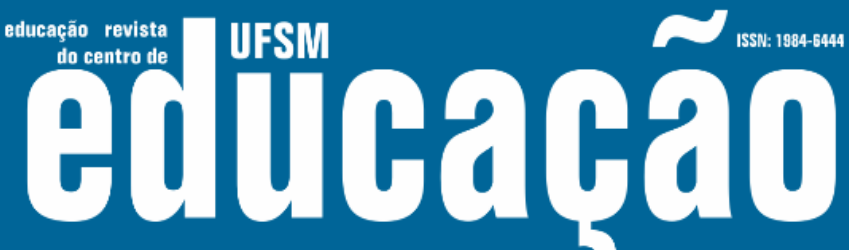 \\ 3}

ISSN: 1984-6444 | http://dx.doi.org/10.5902/1984644434755

Quanto à organização acadêmica, cinco cursos eram ofertados por universidades, 26 por faculdades e dois por centros universitários. A proporção de cursos de Psicologia em universidades no estado da Bahia $(15,6 \%)$ foi inferior à relatada pelo relatório do INEP (BRASIL, 2016b) na macrorregião Nordeste $(31,0 \%)$. O resultado também divergiu do observado em pesquisa anterior, que indicou que, no cenário nacional, cerca de metade dos cursos de Psicologia eram ofertados por universidades (LISBOA; BARBOSA, 2009). Observou-se que universidades tiveram indicadores de desempenho significativamente superiores à faculdades ou centros universitários, conforme Tabela 2. Essas diferenças foram semelhantes às observadas no contexto nacional, em que se constatou que universidades tiveram média na nota geral de 49,0, superior a centros universitários (média $=45,9$ ) e faculdades (média $=44,2) \quad($ INEP, 2016b). O ensino superior ofertado por universidades é desejável, por permitir a integração entre ensino, pesquisa e extensão (LISBOA; BARBOSA, 2012). No estado da Bahia, no entanto, a expansão do ensino superior em Psicologia tem se dado predominantemente na forma de cursos ofertados por faculdades, o que pode comprometer a qualidade da formação do psicólogo.

Tabela 2 - Médias e desvios padrões e resultados dos testes t comparando os indicadores brutos e padronizados do Enade, conforme a organização acadêmica da Instituição de Ensino Superior.

\begin{tabular}{|c|c|c|c|c|c|}
\hline \multirow[t]{2}{*}{ INDICADOR } & \multicolumn{2}{|c|}{ UNIVERSIDADE } & \multicolumn{2}{|c|}{$\begin{array}{c}\text { FACULDADE OU } \\
\text { CENTRO } \\
\text { UNIVERSITÁRIO }\end{array}$} & \multirow[t]{2}{*}{$\begin{array}{l}\text { RESULTADO DO } \\
\text { TESTE T }\end{array}$} \\
\hline & MÉDIA & $\begin{array}{l}\text { DESVIO } \\
\text { PADRÃOO }\end{array}$ & MÉDIA & $\begin{array}{l}\text { DESVIO } \\
\text { PADRÃOO }\end{array}$ & \\
\hline Nota Bruta - FG & 67,4 & 7,481 & 54,59 & 3,885 & $\mathrm{t}_{4,408}=3,754, \mathrm{p}=0,017$ \\
\hline Nota Padronizada - FG & 3,952 & 0,905 & 2,212 & 0,557 & $t_{30}=5,812, p<0,001$ \\
\hline Nota Bruta - CE & 54,7 & 5,912 & 42,0 & 5,157 & $t_{30}=4,960, p<0,001$ \\
\hline Nota Padronizada - CE & 4,085 & 0,834 & 2,292 & 0,728 & $t_{30}=4,960, p<0,001$ \\
\hline Nota Bruta - Geral & 57,9 & 5,979 & 45,1 & 4,640 & $t_{30}=5,410, p<0,001$ \\
\hline $\begin{array}{l}\text { Nota Padronizada - } \\
\text { Geral }\end{array}$ & 4,004 & 1,064 & 1,734 & 0,826 & $t_{30}=5,410, p<0,001$ \\
\hline $\begin{array}{l}\text { Nota dos Concluintes } \\
\text { do Enade }\end{array}$ & 4,052 & 0,818 & 2,272 & 0,657 & $t_{30}=5,374, p<0,001$ \\
\hline
\end{tabular}

Fonte: Elaboração própria.

Quanto à categoria administrativa, 21 cursos tinham fins lucrativos (dois eram ofertados por pessoa jurídica de direito privado - sociedade civil, um por pessoa jurídica de direito privado - sociedade mercantil ou comercial e 18 por instituições 


\section{Autตaดูão}

ISSN: 1984-6444 | http://dx.doi.org/10.5902/1984644434755

privadas), oito por instituições privadas sem fins lucrativos e quatro por pessoa jurídica de direito público (uma estadual e três federais). A predominância de instituições de ensino privadas ( $90,6 \%$ dos cursos de Psicologia da Bahia) também foi observada no contexto nacional, em que corresponderam a $81,9 \%$ dos cursos de psicologia avaliados (BRASIL, 2016b). A maior participação do setor privado na formação de psicólogos no estado da Bahia indica uma educação superior provavelmente orientada para o mercado e para o lucro (LISBOA; BARBOSA, 2009), que além de potencialmente prejudicar a qualidade do ensino, dificulta a inclusão de pessoas oriundas de classes socioeconômicas mais desfavorecidas.

Comparando o desempenho dos cursos de acordo com a categoria administrativa (Tabela 2), aqueles ofertados por instituições públicas $(\mathrm{N}=5)$ tiveram desempenho significativamente superior aos ofertados por instituições privadas $(\mathrm{N}=$ 27), conforme constatado por testes t para amostras independentes. Esse resultado foi semelhante ao encontrado no cenário nacional, conforme relatório do INEP (BRASIL, 2016b), em que os estudantes de instituições públicas obtiveram média mais alta $(51,9)$ que os das instituições privadas $(45,9)$. No caso da Bahia, porém, a diferença entre as médias é ainda maior, chegando a 15 pontos na nota geral bruta. Assim, evidencia-se que a expansão das instituições privadas, embora possa dar a impressão de interiorização e democratização do acesso, tem sido realizada sem os devidos cuidados com a qualidade da formação do psicólogo. O contexto é de mercantilização do ensino, com grande parte das vagas dos cursos de Psicologia da Bahia sendo ofertadas por instituições que priorizam lucro, interesse que entra em conflito com práticas necessárias à gestão de um curso de qualidade, como, por exemplo: a qualificação dos docentes, o investimento em pesquisa e extensão (LISBOA; BARBOSA, 2009). 


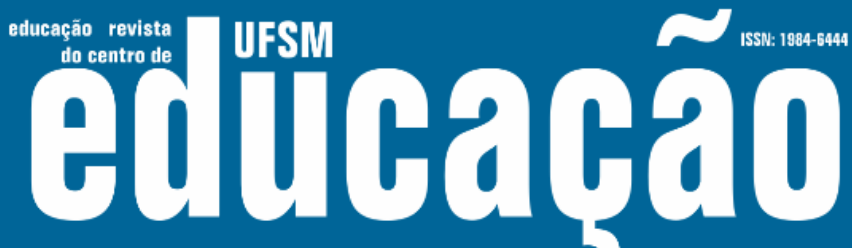 \\ 3}

ISSN: 1984-6444 | http://dx.doi.org/10.5902/1984644434755

Tabela 3 - Médias, desvios padrões e resultados dos testes t comparando os indicadores brutos e padronizados do Enade, conforme a categoria administrativa da Instituição de Ensino Superior.

\begin{tabular}{|c|c|c|c|c|c|}
\hline \multirow{3}{*}{ INDICADOR } & \multirow{2}{*}{\multicolumn{2}{|c|}{ PRIVADA }} & \multirow{2}{*}{\multicolumn{2}{|c|}{ PÚBLICA }} & \multirow[b]{3}{*}{$\begin{array}{l}\text { RESULTADO DO } \\
\text { TESTE T }\end{array}$} \\
\hline & & & & & \\
\hline & MÉDIA & $\begin{array}{l}\text { DESVIO } \\
\text { PADRÃOO }\end{array}$ & MÉDIA & $\begin{array}{l}\text { DESVIO } \\
\text { PADRÃOO }\end{array}$ & \\
\hline Nota Bruta - FG & 54,7 & 3,876 & 69,7 & 6,293 & $t_{30}=-6,725, p<0,001$ \\
\hline Nota Padronizada - FG & 2,231 & 0,556 & 4,255 & 0,695 & $\mathrm{t}_{30}=-6,627, \mathrm{p}<0,001$ \\
\hline Nota Bruta - CE & 42,1 & 5,085 & 57,2 & 2,089 & $t_{30}=-5,815, p<0,001$ \\
\hline Nota Padronizada - CE & 2,305 & 0,717 & 4,441 & 0,295 & $t_{30}=-5,815, p<0,001$ \\
\hline Nota Bruta - Geral & 45,3 & 4,587 & 60,4 & 2,702 & $\mathrm{t}_{30}=-6,373, p<0,001$ \\
\hline Nota Padronizada - Geral & 1,753 & 0,817 & 4,442 & 0,481 & $t_{30}=-6,373, p<0,001$ \\
\hline $\begin{array}{l}\text { Nota dos Concluintes do } \\
\text { Enade }\end{array}$ & 2,287 & 0,649 & 4,394 & 0,336 & $t_{30}=-6,309, p<0,001$ \\
\hline
\end{tabular}

Fonte: Elaboração própria.

Considerando-se que apenas um curso de Psicologia no estado da Bahia foi ofertado por uma universidade privada, não foi possível estabelecer, na presente pesquisa, se as diferenças significativas no desempenho dos cursos de Psicologia do estado da Bahia no Enade 2015 se deveram à organização acadêmica ou à categoria administrativa. É possível afirmar, porém, que cursos de Psicologia ofertados na Bahia por universidades públicas tiveram desempenho superior aos de faculdades e centros universitários privados. Esse resultado é importante em um contexto político em que se discute a participação do Estado na educação superior e há propostas de privatização, pois as evidências indicaram que do ponto de vista da qualidade da formação, a expansão do ensino superior privado tem levado a uma precarização. Em contrapartida, os quatro cursos abertos no contexto da expansão do ensino superior público, fomentados por políticas como o Reuni (BRASIL, 2007), apresentaram bons indicadores, mostrando que o investimento público teve um resultado satisfatório em termos de qualidade da formação dos psicólogos.

Deve-se levar em consideração, ainda, que, conforme a metodologia adotada na presente pesquisa, não foram incluídos cursos fundados mais recentemente e que, portanto, ainda não participaram do Enade. Constatou-se expressivo aumento do número de cursos - todos privados - nos últimos três anos. A literatura tem indicado preocupação em relação ao crescimento dito desordenado do número de cursos, considerando-se que se concentram, principalmente, na rede privada, em cidades que 


\section{Hism

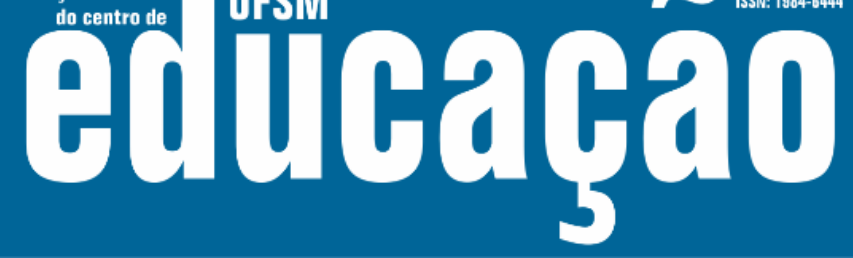

ISSN: 1984-6444 | http://dx.doi.org/10.5902/1984644434755

já concentram o maior número de vagas - pois coincidem com aquelas em que há maior concentração de capital - e com qualidade baixa (LISBOA; BARBOSA, 2009).

Analisando o desempenho dos cursos de Psicologia da Bahia em relação ao conceito Enade em faixas (valores discretos de 1 - mínimo a 5 - máximo), apresentado na Figura 2, cinco cursos (15,6\%) obtiveram o conceito 5, sendo quatro deles de universidades públicas: Universidade do Estado da Bahia, Universidade Federal da Bahia (cursos de Salvador e Vitória da Conquista) e Universidade Federal do Recôncavo da Bahia (UFRB) e um de faculdade privada, a Faculdade Anísio Teixeira de Feira de Santana (FAT). É relevante destacar que apenas nove cursos de Psicologia da macrorregião Nordeste obtiveram conceito máximo no Enade, dos quais oito eram ofertados por universidades e cinco (55,6\%) encontravam-se na Bahia (BRASIL, 2016b).

Em relação aos demais conceitos, três cursos $(9,4 \%)$ obtiveram o conceito 4 . Assim como no contexto nacional e da macrorregião Nordeste (BRASIL, 2016b), o conceito 3 foi mais frequente, obtido por 14 (43,8\%) dos cursos. Dez cursos $(31,3 \%)$ obtiveram o conceito 2. Nenhum curso obteve conceito mínimo (1). Assim, a maior parte dos cursos se manteve em faixas mediana ou fraca (conceitos 3 ou 2).

Figura 4 - Frequências absolutas dos conceitos, em faixas, obtidos por cursos de Psicologia do estado da Bahia no Enade, por categoria administrativa (instituições de ensino públicas ou privadas).

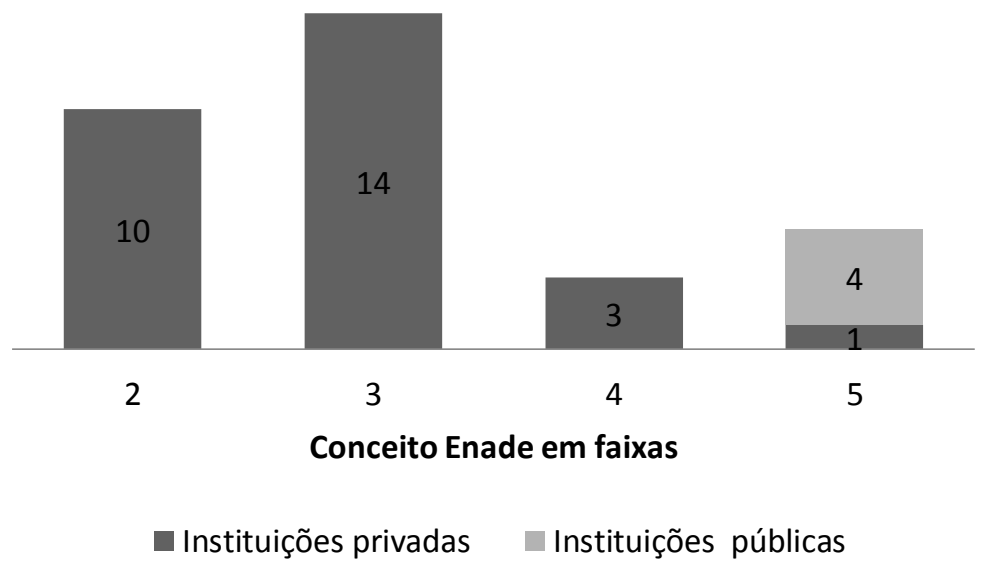

Fonte: Elaboração própria. 


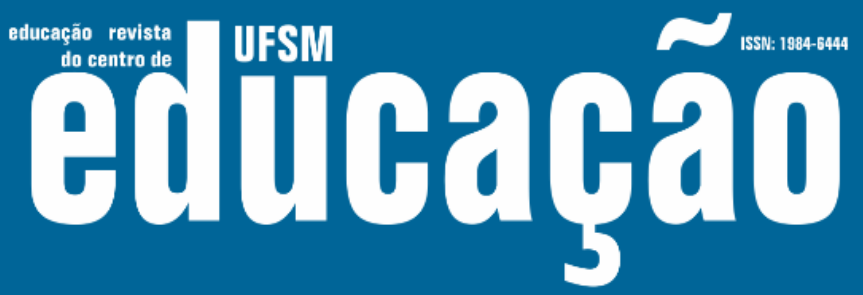

ISSN: 1984-6444 | http://dx.doi.org/10.5902/1984644434755

A interpretação dos resultados expressos em faixas deve levar em conta a metodologia de obtenção dos conceitos, na forma de categorização da Nota dos Concluintes do Enade, que, por sua vez, é calculada a partir das Notas Padronizadas dos componentes FG e FE. Essa padronização leva em consideração não o desempenho que seria considerado ideal na prova, mas o desempenho de um curso em relação aos demais. No contexto da Psicologia, as notas brutas dos indicadores geral, FG e CE situaram-se em torno de 50 (correspondendo à metade da escala de avaliação) e a nota geral máxima dos cursos foi igual a 63,5. Logo, até mesmo os cursos com conceito 5 não tiveram um desempenho notável. Desta forma, os conceitos em faixas, criados para possibilitar a comparação de um curso relativamente aos demais, podem mascarar a realidade de que a qualidade dos cursos - mesmo aqueles com conceito máximo - é mediana para inferior.

Outra limitação do conceito Enade em faixas é a categorização das Notas dos Concluintes do Enade com base em pontos de corte arbitrários, conforme uma tabela (BRASIL, 2016b). Desta forma, cursos com desempenhos semelhantes podem situarse em faixas distintas, caso um deles esteja próximo ao limite superior de uma faixa e o outro esteja próximo ao limite inferior da faixa seguinte (ex.: no presente estudo, um curso com Nota dos Concluintes do Enade $=1,9068$ teve conceito 2, enquanto um curso com 2,0150 teve conceito 3, mas a diferença entre eles é de um décimo); ou cursos com maior diferença de desempenhos podem situar-se na mesma faixa, caso um deles se aproxime do limite inferior e outro do limite superior da mesma (ex.: um curso com Nota dos Concluintes do Enade $=2,0150$ teve conceito 3, assim como um curso com 2,8401, embora a diferença entre eles seja de cerca de oito décimos). Novamente, constata-se que a metodologia adotada pode levar uma pessoa que busque compreender a qualidade dos cursos a enganos na interpretação do desempenho no Enade, superestimando a qualidade de cursos que não apresentaram desempenhos satisfatórios. 


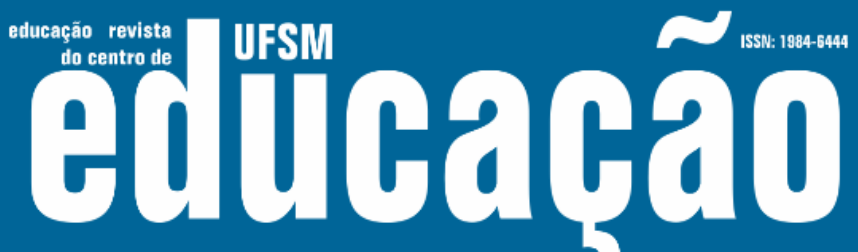

ISSN: 1984-6444 | http://dx.doi.org/10.5902/1984644434755

\section{Considerações}

Ressalta-se que a interpretação dos resultados da presente pesquisa deve levar em conta as críticas ao Enade, no que tange, por exemplo, à desvirtuação da proposta original do SINAES de valorização do caráter formativo da avaliação em detrimento da valorização do aperfeiçoamento da sua função regulatória (FELDMAN; SOUZA, 2016; SOUSA; SEIFFERT; FERNANDES, 2016). Outrossim, entendemos que a qualidade dos cursos jamais pode se reduzir aos indicadores do Enade, aos quais escapam dimensões importantes do processo formativo, como o desenvolvimento de habilidades voltadas à investigação científica e ao trabalho comunitário e coletivo em atividades de extensão.

Não obstante, tais resultados são importantes para balizar discussões acerca da formação do psicólogo na Bahia, caracterizando-se como importantes insumos para tomadas de decisões de docentes, IES e demais atores envolvidos na dinâmica educacional da profissão.

De modo geral, as hipóteses que nortearam o estudo foram confirmadas pelos dados analisados, com exceção da quarta hipótese, cujos resultados foram inconclusivos. Com efeito, é possível afirmar a existência de um processo de interiorização da educação superior no estado, capitaneada pela expansão da rede de ensino privado. A respeito da qualidade dos cursos interiorizados, é importante destacar que não foi constatado um desempenho significativamente distinto em relação aos cursos da capital. Se, por um lado, esse processo de interiorização não esteve associado a uma melhoria na qualidade do processo de ensino-aprendizagem, por outro lado, é preciso considerar relativamente notável a equivalência de desempenho, na medida em que o interior do estado não conta com a mesma disponibilidade de profissionais qualificados em termos de titulação stricto sensu, tradicionalmente associados à qualidade de ensino.

No que tange à qualidade dos cursos, há que considerar que a universidade pública apresenta um desempenho significativamente superior em relação a faculdades e centros universitários privados. Esse dado é particularmente grave no contexto baiano na medida em que há uma predominância de instituições de ensino 




ISSN: 1984-6444 | http://dx.doi.org/10.5902/1984644434755

privadas, da ordem de nove para cada dez IES, superior mesmo ao âmbito nacional, já marcado pela privatização da educação superior. Embora na presente pesquisa não tenha sido possível estabelecer se as diferenças significativas no desempenho dos cursos de Psicologia do estado da Bahia no Enade 2015 se deveram à organização acadêmica ou à categoria administrativa, a predominância do setor privado, majoritariamente estruturado em faculdades e centros, indica um cenário de precarização do ensino.

Ainda a respeito da qualidade dos cursos, infelizmente observou-se um desempenho mediano ou fraco, compatível com a média nacional, com maiores notas no FG que no CE. Assim, se por um lado, registra-se uma performance relativamente competente em habilidades relevantes ao exercício profissional, embora não exclusivas da profissão, como leitura e interpretação de textos, raciocínio indutivo e dedutivo, capacidade de análise e síntese, capacidade de projetar intervenções e propor soluções para situações-problema, e administração de conflitos, por outro lado, é preocupante que tais capacidades se sobressaiam em relação às competências específicas da formação.

Por mais desejável que seja o aumento da cultura geral e da formação éticopolítica e humanística, ensejados, aliás, pela Universidade Nova e Reuni ${ }^{3}$, que buscaram reorganizar a educação superior nos últimos 15 anos, não é aceitável que isso ocorra em detrimento da formação profissional específica, visto que a graduação em Psicologia objetiva a formação de psicólogos generalistas, aptos ao exercício em quaisquer das áreas de atuação da profissão.

Visto que há um desempenho maior no FG do que no CE, é possível especular que o incremento da cultura geral promovido pela formação em Psicologia ocorra em detrimento da aquisição de habilidades próprias da profissão, dado o intervalo limitado, geralmente de cinco anos, para a integralização curricular. Tal cenário poderia ser explicado pelo fato de que o contato com conhecimentos específicos da Psicologia não seria efetivo quando se desse concomitantemente ao desenvolvimento de competências mais amplas requeridas de um profissional de nível superior. Nesse sentido, seria defensável a adoção do regime de ciclos e portanto dos Bacharelados Interdisciplinares ${ }^{4}$, em função do seu foco no desenvolvimento de capacidades ético- 


\section{$\sim$ Eutloabुa}

ISSN: 1984-6444 | http://dx.doi.org/10.5902/1984644434755

políticas e humanísticas, bem como na formação cidadã e no acirramento do compromisso social.

É necessária, portanto, a defesa do fortalecimento da formação geral associada à capacitação profissional específica, de modo a ensejar uma formação completa, competente profissionalmente e socialmente compromissada, própria do que é preconizado pelas Diretrizes Curriculares Nacionais.

Por fim, uma última preocupação que os resultados apontam dizem respeito à metodologia de cálculo do Enade. Tal qual é conduzida, conforme expresso anteriormente, podem mascarar a realidade da qualidade dos cursos, alçando ao conceito máximo aqueles cursos cujos desempenho são de mediano a inferior. Além disso, a categorização das notas com base em pontos de corte arbitrários, acarreta um cenário em que cursos com desenvoltura muito semelhante podem ter conceitos distintos. Assim, constata-se que a metodologia adotada pode levar a enganos na interpretação dos resultados, superestimando a qualidade de cursos que não apresentaram desempenhos satisfatórios e distinguindo conceitualmente cursos com desempenho similar.

Evidentemente, num cenário de privatização da educação superior associada à precarização do ensino, atravessado pela alta competitividade entre as IES, é praticamente certo que elas se aproveitem dessas falhas metodológicas para promover propagandas enganosas acerca da qualidade do seu ensino. E o que é mais grave, sob a tutela de resultados apresentados pelo próprio Estado.

Em suma, a despeito das já apontadas limitações metodológicas deste estudo, é preocupante o cenário de formação em Psicologia na Bahia, com um perverso processo de interiorização marcado pela presença do mercado, sem a devida garantia da qualidade do ensino, e cujo impacto na atuação profissional merece ser avaliado.

\section{Referências}

BASTOS, Antonio Virgílio Bittencourt et al. Formação básica e profissional do psicólogo: uma análise do desempenho das IES no Enade -2006. Aval. psicol., Itatiba, v. 10, n. 3, p. 313-347, dez. 2011. Disponível em: http://pepsic.bvsalud.org/scielo.php?script=sci_arttext\&pid=S1677$04712011000300006 \&$ Ing=pt\&nrm=iso. Acesso em 01 ago. 2018. 


\section{T usm Futlbap̧a}

ISSN: 1984-6444 | http://dx.doi.org/10.5902/1984644434755

BASTOS, Antônio Virgilio Bittencourt; GOMIDE, Paula Inez Cunha. O psicólogo brasileiro: sua atuação e formação profissional. Psicologia: Ciência e Profissão, Brasília, v. 9, n. 1, p. 6-15. Disponível em: http://www.scielo.br/scielo.php?script=sci_arttext\&pid=S1414-98931989000100003. Acesso em 29 abr. 2017.

BRASIL. Decreto no 6.096. Institui o Programa de Apoio a Planos de Reestruturação e Expansão das Universidades Federais - REUNI. Disponível em: http://www.planalto.gov.br/ccivil_03/_Ato2007-2010/2007/Decreto/D6096.htm.

Acesso em 11 Ago. 2018.

BRASIL, Ministério da Educação, Instituto Nacional de Estudos e Pesquisas Educacionais Anísio Teixeira. Resumo técnico: Censo da Educação Superior 2015. $2^{a}$ ed. Brasília: Instituto Nacional de Estudos e Pesquisas Educacionais Anísio Teixeira, 2018.

BRASIL. Lei no 10.861. Institui o Sistema Nacional de Avaliação da Educação Superior - SINAES e dá outras providências, 2004. Disponivel em: http://www.planalto.gov.br/ccivil_03/_ato2004-2006/2004/lei/l10.861.htm. Acesso em 29 Abr. 2017.

BRASIL. Ministério da Educação. Conselho Nacional de Educação. Câmera de Ensino Superior. Resolução no 5. Institui as Diretrizes Curriculares Nacionais para os cursos de graduação em Psicologia, estabelecendo normas para o projeto pedagógico complementar para a Formação de Professores de Psicologia, 2011. Disponível em: http://portal.mec.gov.br/index.php?option=com_docman\&view=download\&alias=7692 -rces005-11-pdf\&Itemid=30192. Acesso em: 01 ago. 2018.

BRASIL. Ministério da Educação. Instituto Nacional de Estudos e Pesquisas Educacionais Anísio Teixeira. Relatório Síntese de Área - Psicologia. Brasília: Instituto Nacional de Estudos e Pesquisas Educacionais Anísio Teixeira, 2016a. Disponível

em: http://download.inep.gov.br/educacao_superior/ENADE/relatorio_sintese/2015/psicol ogia.pdf. Acesso em 29 Abr. 2017.

BRASIL. Ministério da Educação. Instituto Nacional de Estudos e Pesquisas Educacionais Anísio Teixeira. Sinopse Estatística da Educação Superior 2015. Brasília: INEP, 2016b. Disponível em: http://download.inep.gov.br/informacoes_estatisticas/sinopses_estatisticas/sinopses educacao_superior/sinopse_educacao_superior_2016.zip. Acesso em 29 abr. 2017.

BRASIL. Ministério da Educação. Portaria Normativa no 03. Estabelece as regras do Exame Nacional de Desempenho dos Estudantes - Enade, no ano de 2015, 2015. Disponível em: http://download.inep.gov.br/educacao_superior/ENADE/legislacao/2015/portaria_n3_ 06032015_ENADE_2015.pdf. Acesso em 29 Abr. 2017. 


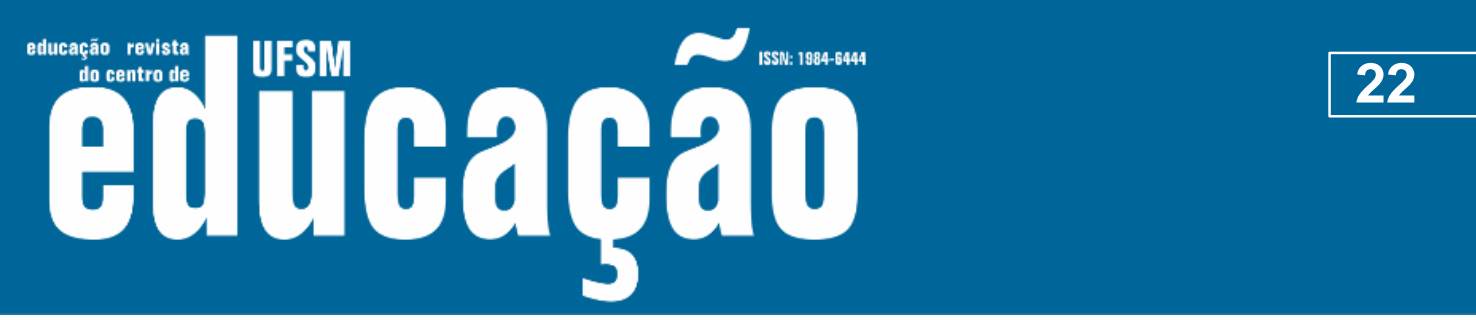

ISSN: 1984-6444 | http://dx.doi.org/10.5902/1984644434755

BRITO, Márcia Regina F. de. O SINAES e o Enade: da concepção à implantação. Avaliação: Revista da Avaliação da Educação Superior, Sorocaba, v. 13, n. 3, p. 841-850, nov. $2008 . \quad$ Disponível em: $\quad$ http://www.scielo.br/scielo.php?script=sci_arttext\&pid=S1414$40772008000300014 \&$ Ing=en\&nrm=iso. Acesso em 29 Abr. 2018.

CHAVES, Vera Lúcia Jacob. Expansão da privatização/mercantilização do ensino superior Brasileiro: a formação dos oligopólios. Educação \& Sociedade, Campinas, v. 31, n. 111, p. 481-500, Jun. 2010. Disponível em: http://www.scielo.br/scielo.php?script=sci_arttext\&pid=S0101$73302010000200010 \&$ Ing=en\&nrm=iso. Acesso em 29 abr. 2017.

CONSELHO FEDERAL DE PSICOLOGIA. A Psicologia brasileira apresentada em números. Disponível em: http://www2.cfp.org.br/infografico/quantos-somos/. Acesso em: 27 nov. 2017.

DIAS SOBRINHO, José. Qualidade, avaliação: do SINAES a índices. Avaliação: Revista da Avaliação da Educação Superior (Campinas), Sorocaba, v. 13, n. 3, p. 817-825, Nov. 2008. Disponível em: http://www.scielo.br/scielo.php?script=sci_arttext\&pid=S1414$40772008000300011 \&$ Ing=en\&nrm=iso. Acesso em 29 Abr. 2017.

FELDMANN, Taise; SOUZA, Osmar de. A governamentalidade e o Exame Nacional de Desempenho De Estudantes - Enade. Avaliação (Campinas), Sorocaba, v. 21, n. 3, p. 1017-1032, Nov. 2016. Disponível em: http://www.scielo.br/scielo.php?script=sci_arttext\&pid=S1414$40772016000301017 \&$ lng=en\&nrm=iso. Acesso em 29 abr. 2017.

HAIR Jr., J.F. et al. Análise multivariada de dados. 6.ed. Porto Alegre, Bookman, 2009. 688p.

LEITÃO, Thiago et al. Uma análise acerca do boicote dos estudantes aos exames de avaliação da educação superior. Revista Brasileira de Educação, Rio de Janeiro, v. 15, n. 43, p. 21-44, abr. 2010. Disponível em: http://www.scielo.br/scielo.php?script=sci_arttext\&pid=S1413-

$24782010000100003 \&$ Ing=en\&nrm=iso. Acesso em 02 ago. 2018.

LIMANA, Amir. Desfazendo mitos: o que estão fazendo com o SINAES?. Avaliação: Revista da Avaliação da Educação Superior, Sorocaba, v. 13, n. 3, p. 869-873, Nov. 2008. Disponível em: http://www.scielo.br/pdf/aval/v13n3/18.pdf. Acesso em 29 Abr. 2017.

LISBOA, Felipe Stephan; BARBOSA, Altemir José Gonçalves. Formação em Psicologia no Brasil: um perfil dos cursos de graduação. Psicologia: Ciência e Profissão, Brasília, v. 29, n. 4, p. 718-737, 2009. Disponível em: http://www.scielo.br/scielo.php?script=sci_arttext\&pid=S1414-

98932009000400006\&lng=en\&nrm=iso. Acesso em 29 abr. 2017. 


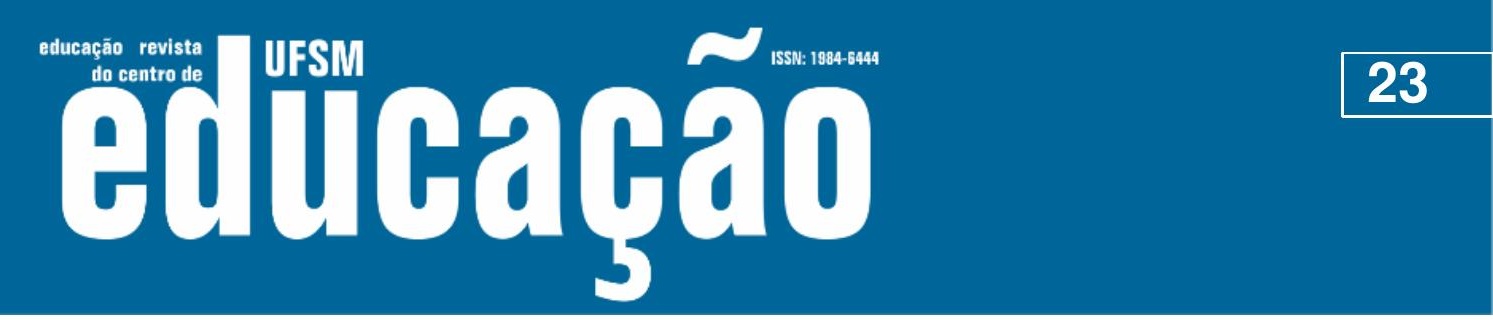

ISSN: 1984-6444 | http://dx.doi.org/10.5902/1984644434755

MARQUES, Antônio Carlos Henriques; CEPÊDA, Vera Alves. Um perfil sobre a expansão do ensino superior recente no Brasil: aspectos democráticos e inclusivos. Perpectivas, Araraquara, v. 42, p. 191-192. Disponível em: https://periodicos.fclar.unesp.br/perspectivas/article/view/5944/4519. Acesso em 11 Ago. 2018.

MINISTÉRIO DA EDUCAÇÃO. Cadastro e-MEC de Instituições e Cursos de Educação Superior. Disponível em: http://emec.mec.gov.br/. Acesso em 11 nov. 2017.

POLIDORI, Marlis Morosini. Políticas de avaliação da educação superior brasileira: Provão, SINAES, IDD, CPC, IGC e outros índices. Avaliação: Revista da Avaliação da Educação Superior, v. 14, n. 2, p. 439-452, Jul. 2009. Disponível em: http://www.scielo.br/pdf/aval/v14n2/a09v14n2.pdf. Acesso em 29 Abr. 2017.

SANTOS, Nálbia de Araújo; AFONSO, Luís Eduardo. Análise do conteúdo das provas da área de Ciências Contábeis: edições do Provão 2002/2003 e do Enade de 2006.Avaliação (Campinas), Sorocaba, v. 21, n. 2, p. 387-414, jul. 2016. Disponível em: http://www.scielo.br/scielo.php?script=sci_arttext\&pid=S1414$40772016000200387 \&$ lng=en\&nrm=iso. Acesso em 02 ago. 2018.

SILVA JUNIOR, João dos Reis; SGUISSARDI, Valdemar. A nova lei de educação superior: fortalecimento do setor público e regulação do privado/mercantil ou continuidade da privatização e mercantilização do público?. Revista Brasileira de Educação, Rio de Janeiro, n. 29, p. 5-27, Ago. 2005. Disponível em: http://www.scielo.br/scielo.php?script=sci_arttext\&pid=S1413-

$24782005000200002 \&$ Ing=en\&nrm=iso. Acesso em 29 abr. 2017.

SOUSA, José Vieira de; SEIFFERT, Otília Maria L. B.; FERNANDES, Ivanildo Ramos. Acesso e expansão de cursos de graduação de alta qualidade no Brasil: outros indicadores de qualidade de vida para a educação superior. Educação em Revista, Belo Horizonte, v. 32, n. 4, p. 19-47, Dez. 2016. Disponível em: $\quad$ http://www.scielo.br/scielo.php?script=sci_arttext\&pid=S0102$46982016000400019 \&$ Ing=en\&nrm=iso. Acesso em 29 Abr. 2017.

SOUZA, Marilene Proença Rebello de; BASTOS, Antônio Virgílio; BARBOSA, Deborah Rosária. Formação básica e profissional do psicólogo: análise do desempenho dos estudantes no Enade -2006. Avaliação Psicológica, Itatiba, v. 10, n. 3, p. 295-312, dez. 2011. Disponível em: http://pepsic.bvsalud.org/scielo.php?script=sci_arttext\&pid=S1677-

$04712011000300005 \& \mathrm{lng}=$ pt\&nrm=iso. Acesso em 01 ago. 2018.

TEIXEIRA, Anísio. Uma perspectiva da educação superior no Brasil. Revista Brasileira de Estudos Pedagógicos, v. 50, n. 111, p. 21-82, 1968. 


\section{N ussm

ISSN: 1984-6444 | http://dx.doi.org/10.5902/1984644434755

VERHINE, Robert. Avaliação e regulação da educação superior: uma análise a partir dos primeiros 10 anos do SINAES. Avaliação: Revista da Avaliação da Educação Superior, Sorocaba, v.20, n. 3, 603-619, nov. 2015. Disponível em: http://www.scielo.br/scielo.php?script=sci_arttext\&pid=S1414-

$40772015000300603 \&$ Ing=en\&nrm=iso. Acesso em 29 Abr. 2017.

VERHINE, Robert; FREITAS, Antônio Roberto da Silva Monteira de. A avaliação da educação superior: modalidades e tendências no cenário internacional. Revista Ensino Superior Unicamp, Campinas, v. 3, n. 7, p. 16-39, 2012. Disponível em: https://www.revistaensinosuperior.gr.unicamp.br/artigos/a-avaliacao-da-educacaosuperior-modalidades-e-tendencias-no-cenario-internacional. Acesso em 29 Abr. 2017.

\section{Correspondência}

Caio Rudá - Universidade Federal do Sul da Bahia - Rodovia de Acesso para Itabuna, km 39 - Ferradas, CEP 45613-204, Itabuna, Bahia, Brasil.

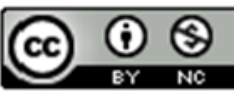

This work is licensed under a Creative Commons Attribution-NonCommercial 4.0 International (CC BY-NC 4.0)

\section{Notas}

\footnotetext{
${ }^{1}$ Desde 2008, o cálculo do conceito do Enade de cada curso considera apenas a nota dos estudantes concluintes, inscritos em condição regular e que participaram do exame. Não é atribuído conceito Enade a cursos com menos de dois participantes, para preservar a identidade dos estudantes (BRASIL, 2016b).

${ }^{2}$ As informações apresentadas foram calculados com base em dados disponibilizados pelo Instituto Brasileiro de Geografia e Estatística (IBGE, 2017) e o Conselho Federal de Psicologia (CFP, 2017).

${ }^{3}$ O REUNI, que teve que teve como objetivo ampliar o acesso e a permanência na educação superior, por meio de um melhor aproveitamento de recursos físicos e humanos das universidades federais, teve como uma das bases o projeto de Universidade Nova, elaborada pela Universidade Federal da Bahia, que propunha, entre outras inovações, a transformação da arquitetura acadêmica linear, voltada para a formação profissional especializada na graduação. Nesse sentido, advogava a implementação de regimes de ciclos de formação, pautado em bacharelados interdisciplinares como etapa propedêutica às formações profissionais.

${ }^{4}$ Os Bacharelados Interdisciplinares são programas de formação graduada de natureza generalista, organizados em grandes áreas do conhecimento, como por exemplo: artes, ciências, humanidades, saúde etc. Tem como prerrogativas a interdisciplinaridade, flexibilização curricular, incremento da autonomia estudantil, valorização da pluralidade epistêmica, entre outras.
} 